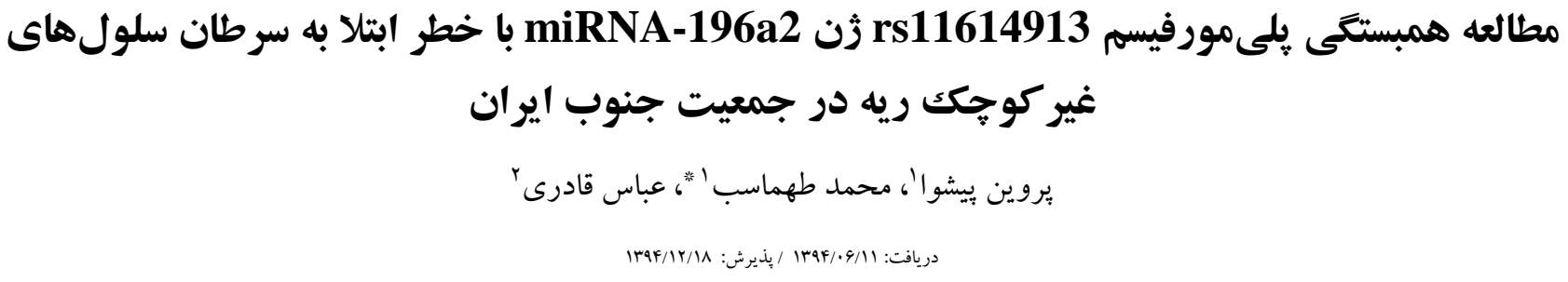

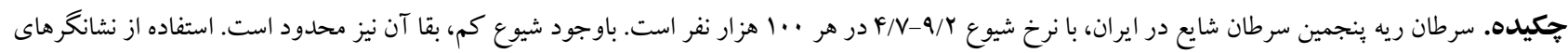

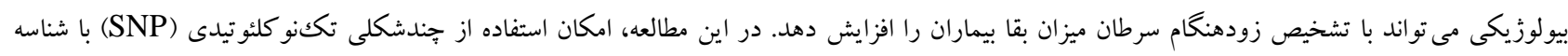

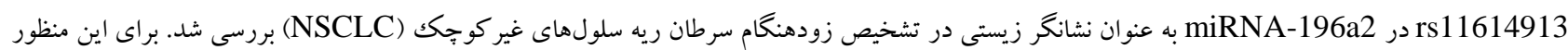

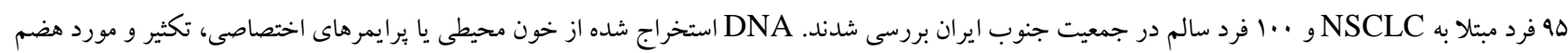

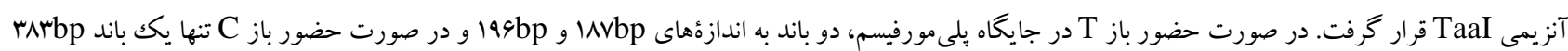

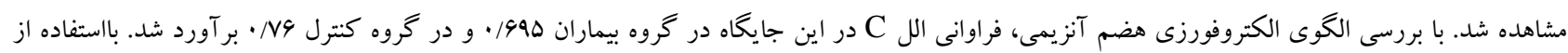

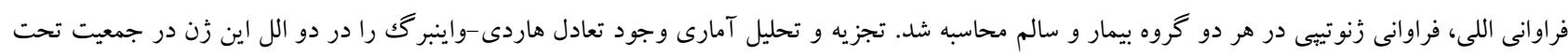

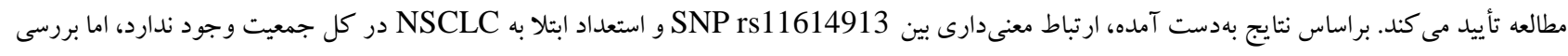

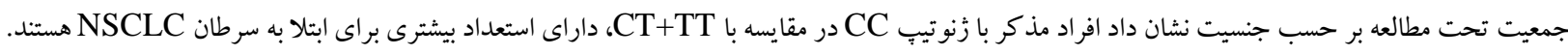
وازههاى كليدى. ميكروRNA، سرطان سلولهاى غير كوخك ريه، بلىمورفيسم تككنو كلئوتيدى

\title{
Association between gene polymorphism rs11614913 in microRNA196a2, with Non-small cell lung cancer risk in the population of southern Iran
}

\author{
Parvin Pishva $^{1}$, Mohammad Tahmaseb $^{1 *}$, Abbas Ghaderi $^{2}$ \\ Received: 01/09/2015 / Accepted: 08/03/2016
}

${ }^{1}$ Department of Cell and Molecular Biology, Faculty of Biological Sciences, Kharazmi University, Iran

${ }^{2}$ Institute for Cancer Research, Shiraz University of Medical Sciences, Shiraz, Iran

"Corresponding author: tahmaseb@khu.ac.ir

\begin{abstract}
Lung cancer is the fifth most common cancer in Iran, with rates of 4.7 to 9.2 per 100 thousand populations. Despite the low incidence, survival is not promising. Using biological markers could lead to longer survival rate in patients due to early diagnosis. In this study, we evaluated the association of SNP rs11614913 in mir-196a2 with risk of non-small cell lung cancer (NSCLC) in population of southern Iran. SNP rs11614913 in miR-196a2 was assayed in 95 lung cancer patients and 100 controls. The extracted DNA from peripheral blood was amplified using specific primers followed by TaaI digestion. Based on the nucleotide base in this SNP (T or C) two different patterns were produced. In case of T, two bands (187bp and 196bp) and in case of C just one band (383bp) was generated. Analysis of electrophoretic pattern of digestion products revealed that the frequencies of C allele for SNP rs11614913 miR-196a2 were 0.695 in patients and 0.76 in controls. The statistical analysis indicates the presence of Hardy-Weinberg equilibrium between the two alleles in the population studied $(p>0.05)$. Based on the results in this study, no significant association between SNP rs11614913 and susceptibility to NSCLC was found. However, male participants who possess TC/TT genotypes showed high risk for NSCLC compared to those possessed CC genotypes.
\end{abstract}

Keywords. micro RNA, non-small cell lung cancer, SNP 
شناسايىSNP أو و تعيين همبستخى آنها با بيمارىهايى نظير

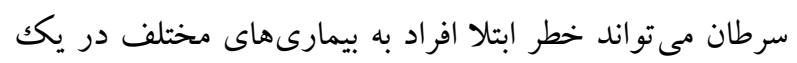
جمعيت را مشخص كند. كوجکك غير كد كننده به طول حدود •rNA ،miRNA

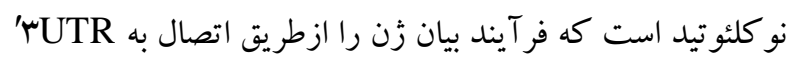
(به طور عمده)، ه'UTR يا در برخى موارد به ناحئ كد كنندة هدRNA كاهش آن مىشوند (Filipowicz et al., 2008). علاوهبراين مى تواند در زنهايى كه واسطة تنظيم زنهاى miRNA هستند،

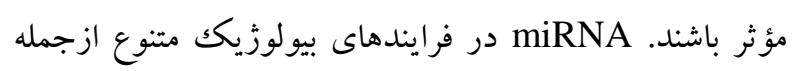

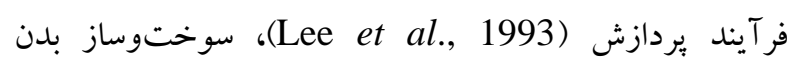

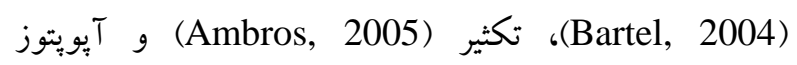
(Ambros, 2004) غيرطبيى miRNA در سرطانها، مطالعات بسيارى در زمينة نقش miRNA در رشد تومورها و سرطانزايى بهواسطة فعالكردن انكوزنها و تخريب زنهاى سركوب

است (Lujambio et al., 2012).

زن miRNA-196a2 (كه آن را mir-196a2 نيز مىنامند)

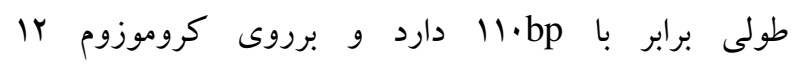

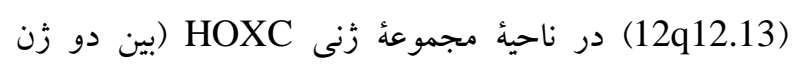
HoxC10 و قرار دارد (Chen et al., 2011)

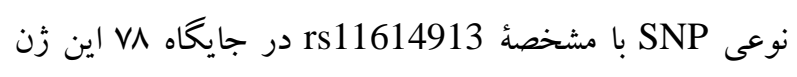
كشف شده است كه در آن بهطور معمول باز C قرار دارد، ولى در برخى افراد باز T جايگزين آن شده است. اخيراً مطالعات

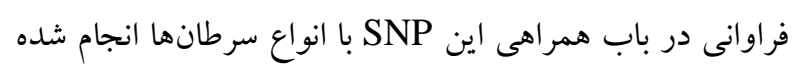

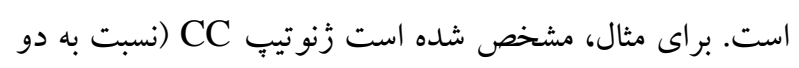
زنوتيب TT و TC) با افزايش خطر ابتلا به سرطانهاى حنجره Min et al., ) و كلور كتال (Christensen et al., 2010) 2011) همراه است. در ايران نيز بررسى احتمال همراهى اين

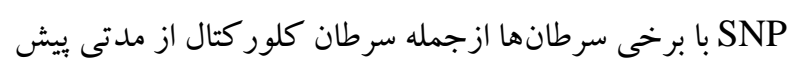
آغاز شده است. بهعلت اهميت سرطان ريه، هدف اين تحقيق

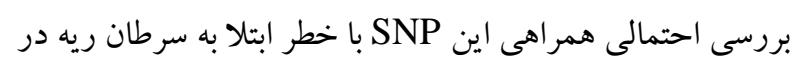
جامعd ايرانى است.

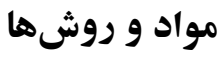

مقدمه

سرطان ريه يكى از سرطانهاى شايع در سطح جهان است و

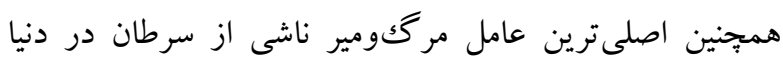

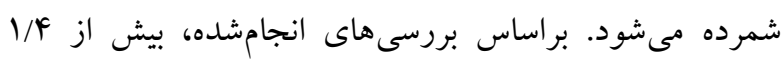

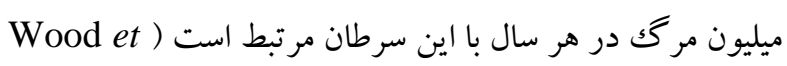

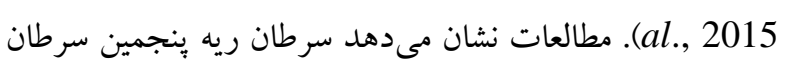

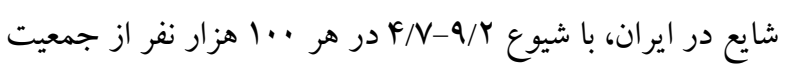

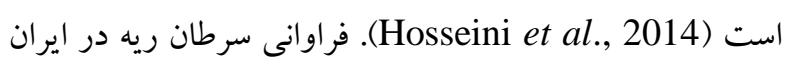
كمتر از ارويا و ايالت متحد امريكا است. در كشور ما، سرطان

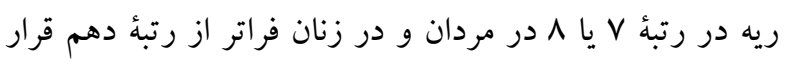
دارد درحالى كه در مقياس جهانى، اين سرطان در مردان و زنان

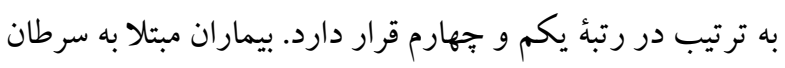

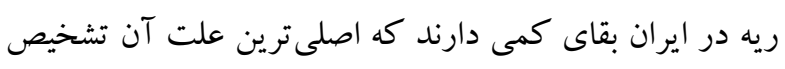
ديرهنكام آن است (Hajmanoochehri et al., 2014).

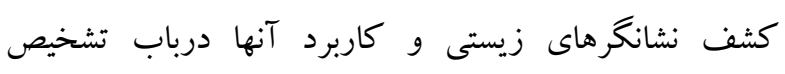

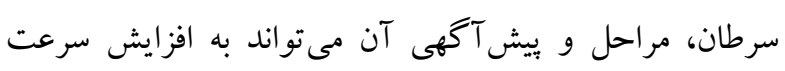
تشخيص زودهنگام و بهبود كيفيت در درمان بيمار منجر شود آنو

.(Hu et al., 2008)

سرطان سلول غير كوجکك ريه (Lung Cell Non-Small)

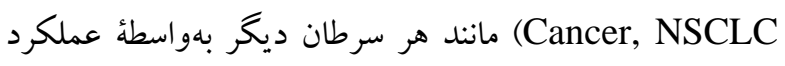

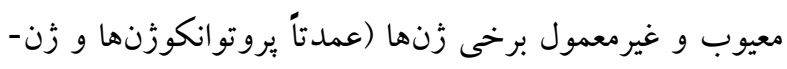

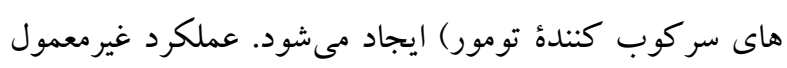

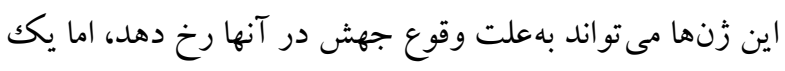

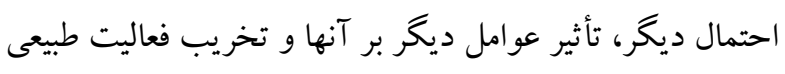

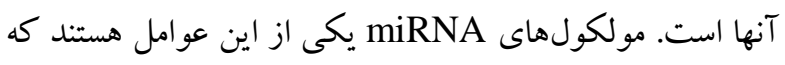

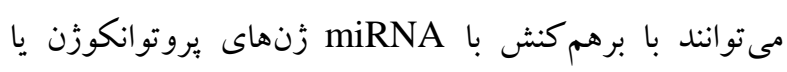

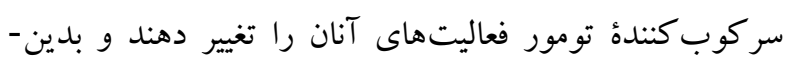

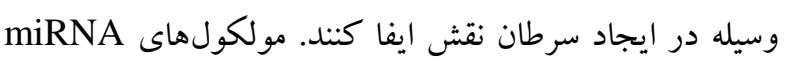
خود بايد دجار تغيير شود تا موجب تغيير در عملكرد بيان يروتوانكوزنها يا زنهاى سركوب كنندهُ تومور شوند.

يكى از عواملى كه مى تواند بر عملكرد miRNA تأثير بكذارد،

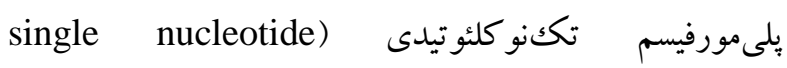
(polymorphism, SNP تأثير SNP بر عملكرد miRNA (ازجمله تأثير آن بر استعداد به به برات ابتلا به سرطان و ديخر بيمارىها) انجام شده است. 
درجة سانتى گراد، اتصال برايمر به DNA بهمدت •F ثانيه در

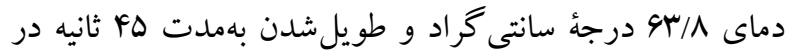
دماى Vr درجة سانتى گر اد انجام شد.

در آخرين مرحله، طويلشدن نهايى بهمدت ه دقيقه در دماى Vr درجهُ سانتى گراد انجام شد. براى اطمينان از حضور و كيفيت باند تكثيرشده محصول نهايى بر زل اكارز ب درصد الكتروفورز شد و سيس با Green Viewer رنغك آميزى شد.

\section{تعيين زنوتيب mir-196a2}

براى تعيين زُنوتيبهاى حاصل از بلىمورفيسم rs11614913 از روشPCLP استفاده شد. محصول PCR تحت اثر آنزيم

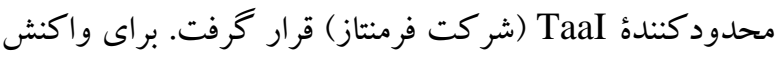
هضم آنزيمى، محلولى حاوى ·اميكروليتر محصول PCR همراه با ץ ماكروليتر بافر تانگو 10X، r واحد آنزيم TaaI و 9 ميكرو ليتر از لهيه و در دماى 90 درجهُ سانتى گر اد بهمدت r ساعت انكوبه شد. محصول هضمشده براى تعيين زنو تيب بر زل اكارز ب درصد الكتروفورز شد.

نتايج

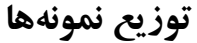

در اين مطالعه ها بيمار مبتلا به سرطان سلولهاى غير كوجكك ريه

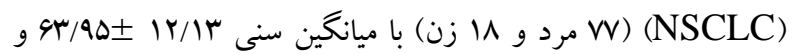

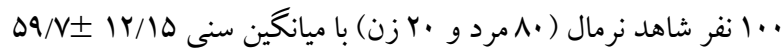

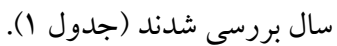

تخليص DNA و تكثير خن miR-196a2

مقدار جذب DNA تخليصشده در دو طول موج • • و و •وץ نانومتر اندازءگيرى شد. نسبت A260/A280 براى اكثر نمونهها ما بين

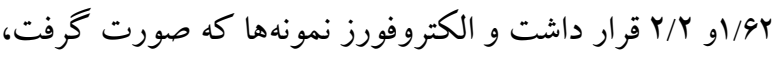
نيز مؤيد حفظ تماميت DNA زنوم بود. محصول PCR نيز با اندازهُ بهدست آمده از مطالعات بيوانفورماتيكى (rArbp) مطابقت داشت (شكل ra (1).
جمع آورى نمونه

در اين مطالعه موردى- شاهدى 90 بيمار مبتلا (N ز زن و

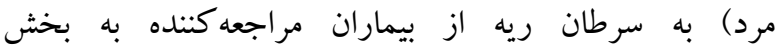
برونكوسكويى درمانگاه فوق تخصصى شهيدفيهى شيراز و ..1

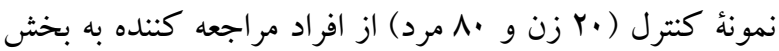
برونكوسكويى درمانكاه فوق تخصصى شهيدفقيهى شيراز بدون

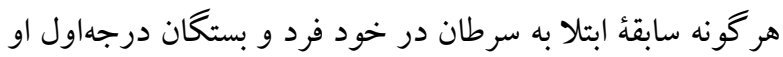

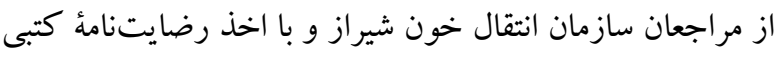

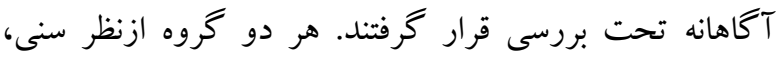
جنسى و جغر افيايى در دامنٔ تقريباً يكسانى قرار داشتند.

استخراج DNA انومى

در اين مطالعه استخراج DNA به روش خارجسازى نمكى با بتفاده از آنزيم ليز كننده بروتئيناز (Miller et al., 1988) K انجام شد. كيفيت DNA استخر اجشده بهوسيلة الكتروفورز و كميت آن بهروش نورسنجى تحت بررسى قرار گرفت.

تكثير ذن mir-196a

زن mir-196a2 از روى مطالعات قبلى و با استفاده از F: با توايمرهاى اختصاصى (Mirtalebi et al., 2014) R: 5': , 5': GTCTACTCTCTAGTCCTTAGG TTGAGAGGACGGCATAAAGC تكثير شد. واكنش

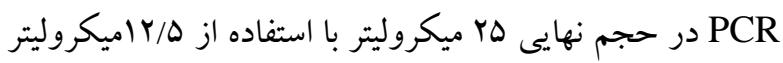
Master Mix دو يرايمر و صد نانو گرم DNA استخراج شده زنومى انجام شد.

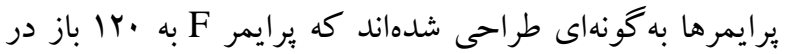
بالادست و يرايمر R به •l باز در باييندست زن متصل مى شود و بدين ترتيب يكك محصول PCR، يك قطعة برش جفت بازى خواهد شد. در اين صورت، موقعيت SNP در جايكاه 191 از انتهاى بر ايمر F قرار خو اهد كرفت (شكل (). واكنش زنجيرهاى بليمراز با بروفايل دمايى بهترتيب زير انجام شد: واسرشت اوليه بهمدت ه دقيقه در دماى هو درجهُ سانتى -

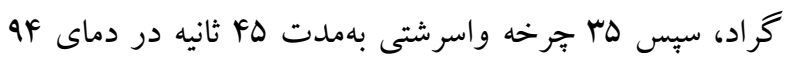




$\begin{array}{lcccll}\text { OLIGO } & \text { start } & \text { len } & \text { tm } & \text { gc\% } & \text { seq } \\ \text { LEFT PRIMER } & 1 & 21 & 53.11 & 47.62 & \text { GTCTACTCTCTAGTCCTTAGG } \\ \text { RIGHT PRIMER } & 383 & 20 & 57.98 & 50.00 & \text { TTGAGAGGACGGCATAAAGC }\end{array}$

\section{PRODUCT SIZE: 383}

1 GTCTACTCTCTAGTCCTTAGGGAGGTTGTGGGGGCGGAAAGGGGGACGGGGCTGAATTTC >>>>>>>>>>>>>>>>>>>

61 TTCCTTCCCCAACCCCCTTCCCTTCTCCTCCAGATAGATGCAAAGCTGAATCTCCCGCCC

121 TGCTCGCTCAGCTGATCTGTGGCTTAGGTAGTTTCATGTTGTTGGGATTGAGTTTTGAAC

181 TCGGCAACAAGAAACT`GTCTGAGTTACATCAGTCGGTTTTCGTCGAGGGCCCCAACCCAC

241 СTCTCCCACTCCTACCCTCCCCAGTGGGACTGCCCCACTGCCCCCTCCCAGATAGGGCAA

301 AGTGGGTGCAGACCAAGGAGGACAAGCTGTGAGTGGGGTTGCAGAACAAGTCTGGAGAAC

361 CCTGCTTTATGCCGTCCTCTCAA

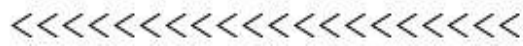

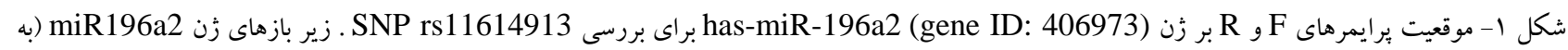

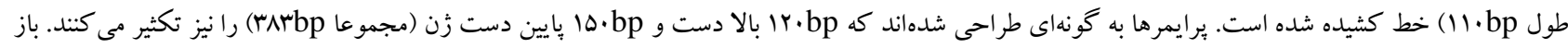

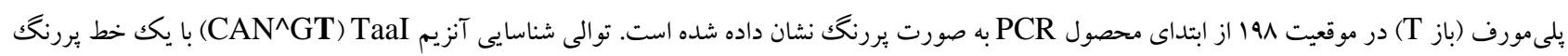

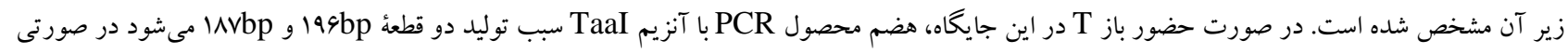

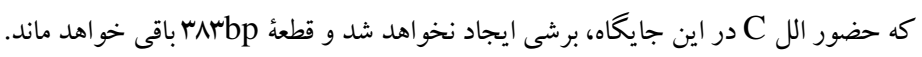

Fig. 1. The position of $F$ and $R$ primers on miR196a2.The sequences of the gene (110bp long) is underlined. The primers were designed for $120 \mathrm{bp}$ upstream and $150 \mathrm{bp}$ downstream of the gene. Therefore the PCR product is 383bp long. The polymorphic base ( $\mathrm{T}$, which is bold in the figure) is on the position of 198 from 5 ' end of PCR product. The restriction site for TaaI $\left(\mathrm{CAN}^{\wedge} \mathrm{GT}\right.$ ) is underlined (with thick line).In case of presence of $\mathrm{T}$ base, the digestion of PCR products are 196 and 187 base pairs. Otherwise, there was no digestion and the fragment of 383bp remains.

p=0.02, OR, 1.78; 95\% CI, 1.08 to ) معندارى بود

$$
\text { (جدول ( } 2.93 \text { ) ( }
$$

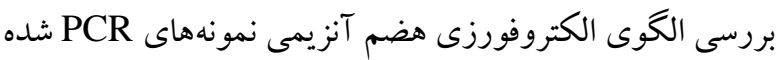

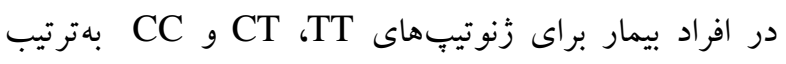

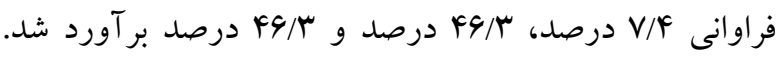

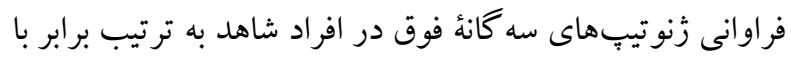

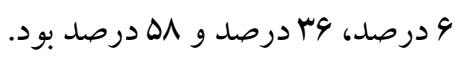

\section{فراوانى زنوتيبى و اللى}

با توجه به نتايج آمارى بهدست آمده هيجيك البك از سه زنوتيب

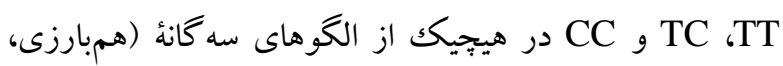
غالبيت و مغلوبيت) تأثيرى بر خطر سرطان NSCLC نداشت (جدول Y). در ضمن اكر جه فراوانى آللى اين SNP در افراد

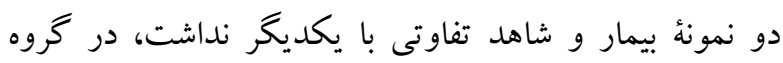
مردان فراوانى اللى در دو نمونهُ بيمار و شاهد داراى تفاوت 


$$
\begin{aligned}
& \text { فراوانىهاى مشاهدهشده براى دو الل اين SNP وجود تعادل } \\
& \text { هاردى-واينبر گك را در دو گروه بيمار و شاهد نشان داد } \\
& .(\mathrm{p}>0.05)
\end{aligned}
$$

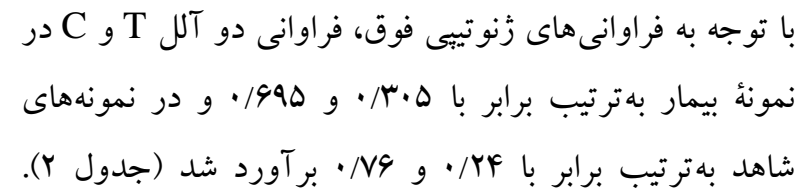$$
\text { جدول ا- توزيع برخى از متغيرها بين دو گروه مبتلايان به سرطان NSCLC و افراد كنترل. }
$$

Table 1. Distribution of selected variables between non-small cell lung cancer patient and control subjects.

\begin{tabular}{ccc}
\hline & \multicolumn{2}{c}{$\mathrm{n}(\%)$} \\
\cline { 2 - 3 } Variables & Patients & Control \\
Age $(\mathrm{y})($ mean \pm SD $)$ & $\mathrm{n}=95$ & $\mathrm{n}=100$ \\
Age $(\mathrm{y})$ & $63.95 \pm 12.13$ & $59.7 \pm 12.15$ \\
$\geq 60$ & & $57(57)$ \\
$<60$ & $60(63)$ & $43(43)$ \\
Gender & $35(37)$ & \\
Male & & $80(80)$ \\
Female & $77(81)$ & $20(20)$ \\
\hline
\end{tabular}

SD: standard deviation. $p$-value was revealed by two-sides Chi-square test
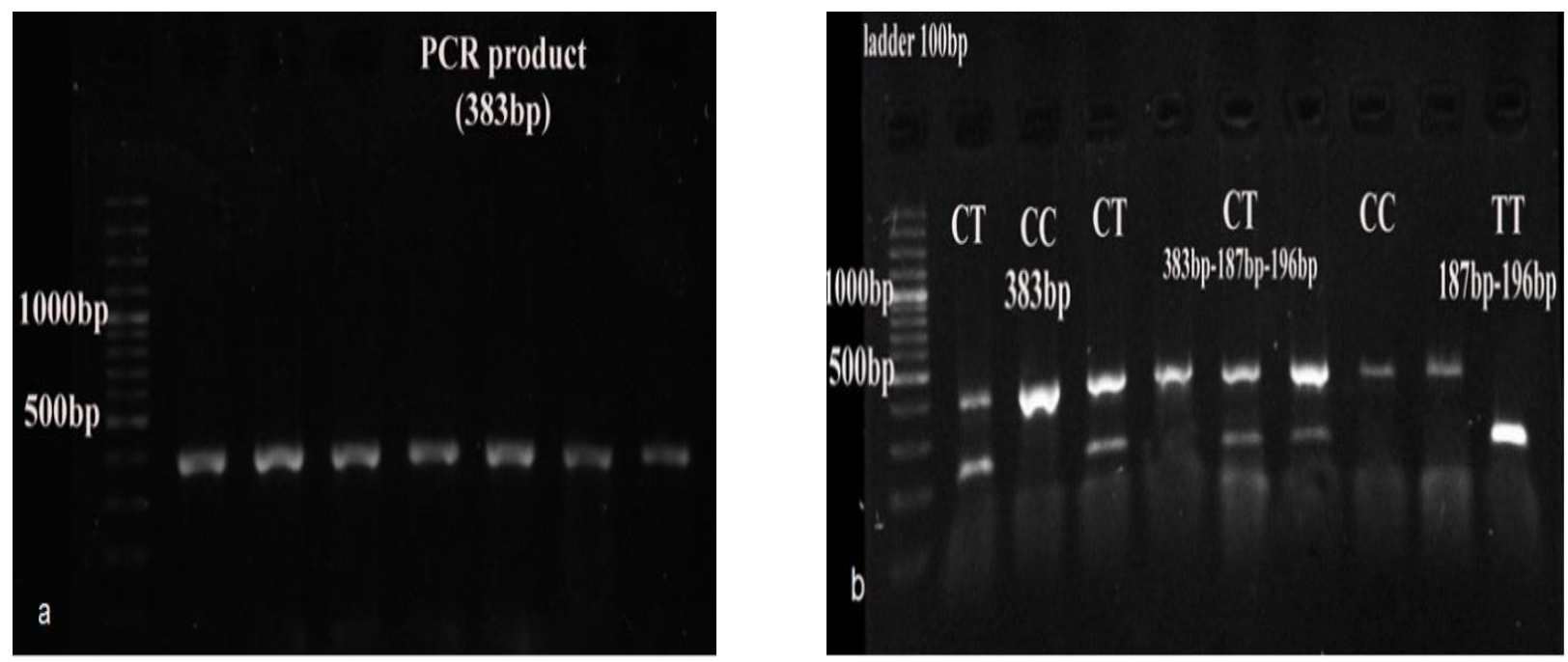

شكل r- بررسى محصول PCR و محصول هضمشده بر زل آكاروز a) اكتروفورز محصول PCR: اندازهٔ قطعة تكثيرشده برابر با rیم جفت باز است. b) الكتروفورز

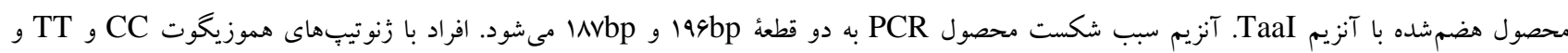
هتروزيخوت CT در عكس مشخص شدهاند.

Fig. 2. Examine of the PCR products and the digestion products on the agarose gel. a) PCR products electrophoresis: the products are 383 base pare long. b) Digestion products electrophoresis: digestion of PCR products with TaaI could produce 196bp and 187bp fragment (in TT individuals), 383bp, 196bp, 187bp (in CT individuals) and 387bp (in CC individuals). 


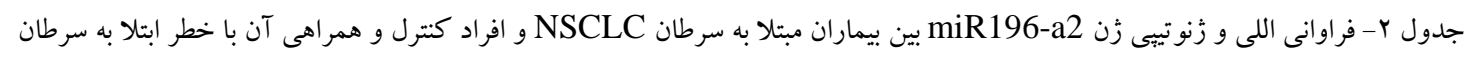

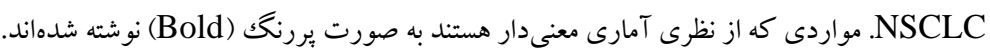

Table 2. miR-196a allelic and genotype frequencies between non-small cell lung cancer patient and control subjects and their association with non-small cell lung cancer risks.

\begin{tabular}{|c|c|c|c|c|c|}
\hline \multirow{2}{*}{ Variables } & \multicolumn{4}{|c|}{$\mathrm{n}(\%)$} & \multirow{2}{*}{$P$-value } \\
\hline & Genotypes & Patient(n=95) & Control(n=100) & $\mathrm{OR}(95 \% \mathrm{CI})$ & \\
\hline \multicolumn{6}{|l|}{ Total } \\
\hline & $\mathrm{T}$ allele & $58(30.5)$ & $48(24)$ & 1 & \\
\hline & $\mathrm{C}$ allele & 132(69.5) & 152(76) & $1.40(0.89-2.18)$ & 0.18 \\
\hline & TT & $7(7.4)$ & $6(6)$ & 1 & 0.26 \\
\hline & $\mathrm{TC}$ & $44(46.3)$ & $36(36)$ & $0.95(0.29-3.09)$ & \\
\hline & $\mathrm{CC}$ & $44(46.3)$ & $58(58)$ & $1.54(0.48-4.90)$ & \\
\hline & TTvsTC/CC & $88(92.6)$ & $94(94)$ & $1.31(0.77-2.21)$ & 0.92 \\
\hline & CCvsTC/TT & $51(53.7)$ & $42(42)$ & $0.62(0.35-1.10)$ & 0.14 \\
\hline \multicolumn{6}{|l|}{$\operatorname{Age}(y)$} \\
\hline \multirow[t]{7}{*}{$>60$} & $\mathrm{~T}$ allele & $33(28.9)$ & $26(23)$ & 1 & \\
\hline & $\mathrm{C}$ allele & $81(71.1)$ & $76(67)$ & $1.19(0.65-2.17)$ & 0.68 \\
\hline & $\mathrm{TT}$ & $4(7)$ & $5(9.8)$ & 1 & 0.40 \\
\hline & $\mathrm{TC}$ & 25(43.9) & $16(31.4)$ & $0.51(0.12-2.20)$ & \\
\hline & $\mathrm{CC}$ & $28(49.1)$ & $30(58.8)$ & $0.86(0.21-3.52)$ & \\
\hline & TTvsTC/CC & $53(93)$ & $46(90)$ & $0.69(0.17-2.74)$ & 0.86 \\
\hline & CCvsTC/TT & $29(50.9)$ & $21(41)$ & $0.67(0.31-1.45)$ & 0.41 \\
\hline \multirow[t]{7}{*}{$<60$} & $\mathrm{~T}$ allele & $25(32.9)$ & $22(22.5)$ & 1 & \\
\hline & $\mathrm{C}$ allele & $51(67.1)$ & $76(77.5)$ & $1.69(0.86-3.32)$ & 0.17 \\
\hline & $\mathrm{TT}$ & $3(7.9)$ & $1(2)$ & 1 & 0.22 \\
\hline & $\mathrm{TC}$ & $19(50)$ & $20(41)$ & $3.16(0.3-33.0)$ & \\
\hline & $\mathrm{CC}$ & $16(42.1)$ & $28(57)$ & $5.25(0.5-54.78)$ & \\
\hline & TTvsTC/CC & $35(92.1)$ & $48(98)$ & $4.11(0.41-41.2)$ & 0.44 \\
\hline & CCvsTC/TT & $22(57.9)$ & $21(43)$ & $0.54(0.23-1.28)$ & 024 \\
\hline \multicolumn{6}{|l|}{ Sex } \\
\hline \multirow[t]{7}{*}{ Male } & $\mathrm{T}$ allele & $52(33.8)$ & $35(23)$ & 1 & \\
\hline & $\mathrm{C}$ allele & $102(66.2)$ & 119(77) & $1.73(1.05-2.87)$ & 0.04 \\
\hline & $\mathrm{TT}$ & $7(9.1)$ & $5(6.5)$ & 1 & 0.05 \\
\hline & $\mathrm{TC}$ & $38(49.4)$ & $25(32.5)$ & $0.92(0.26-3.23)$ & \\
\hline & $\mathrm{CC}$ & $32(41.5)$ & $47(61)$ & $2.06(0.6-7.05)$ & \\
\hline & TTvsTC/CC & 70(90.9) & $72(93.5)$ & $1.44(0.44-4.75)$ & 0.76 \\
\hline & CCvsTC/TT & $45(58.4)$ & $30(39)$ & $0.45(0.24-0.86)$ & 0.02 \\
\hline \multirow[t]{7}{*}{ Female } & $\mathrm{T}$ allele & $6(16.7)$ & $13(36)$ & 1 & \\
\hline & $\mathrm{C}$ allele & $30(83.3)$ & $23(64)$ & $0.35(0.12-1.07)$ & 0.11 \\
\hline & $\mathrm{TT}$ & 0 & $1(4)$ & 1 & 0.38 \\
\hline & $\mathrm{TC}$ & $6(33.3)$ & $11(48)$ & $0.6(0.02-16.68)$ & \\
\hline & $\mathrm{CC}$ & $12(66.7)$ & $11(48)$ & $0.31(0.01-8.31)$ & \\
\hline & TTvsTC/CC & $18(100)$ & $22(96)$ & $0.41(0.02-10.55)$ & 0.89 \\
\hline & CCvsTC/TT & $6(33.3)$ & $12(52)$ & $2.1(0.61-7.82)$ & 0.37 \\
\hline
\end{tabular}




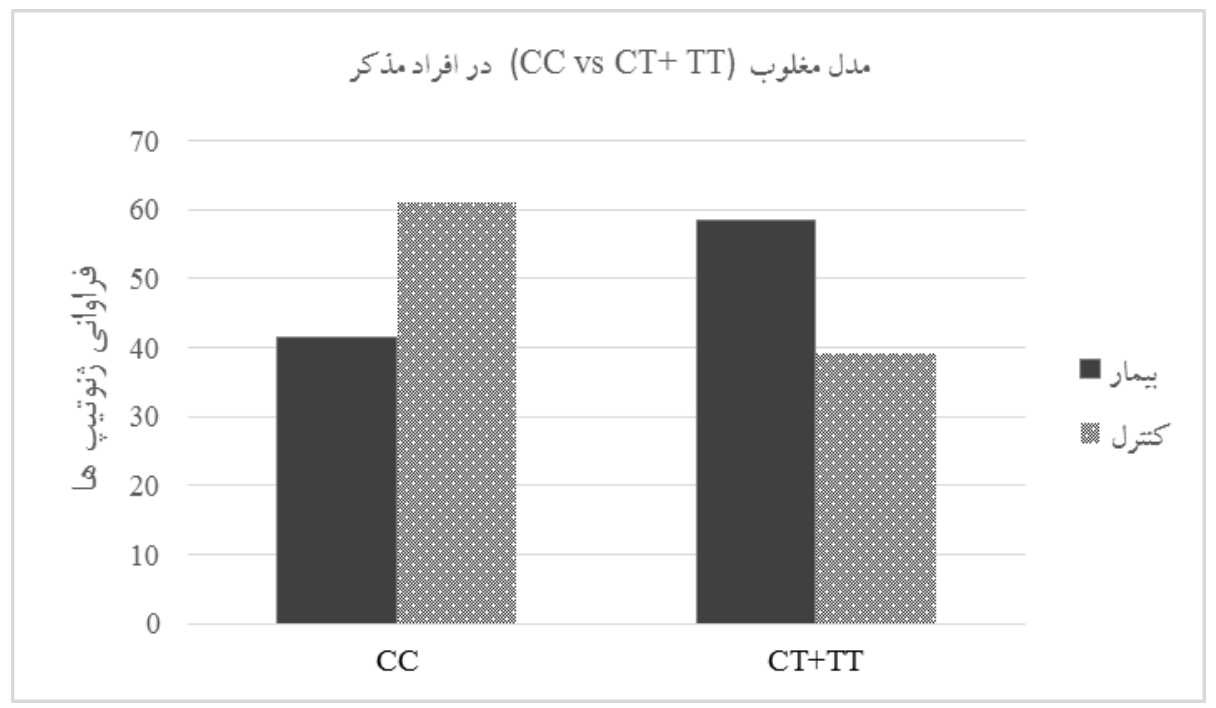

شكل ب- نمودار فراوانى مدل مغلوب (CC vs CT+TT) در افر اد مذكر دو گروه بيمار و شاهد. بررسى آمارى نشاندهندة اختلاف معنىدار بين مردان بيمار و شاهد

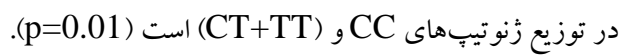

Fig. 3. Comparison of the recessive model (CC vs CT+TT) among male subjects in patients and controls. Statistic analysis showed that there was significant difference in $\mathrm{CC}$ and $\mathrm{CT}+\mathrm{TT}$ genotype distribution in males in two groups $(\mathrm{p}=0.2)$

ممكن است هميجون انكوزن يا زنهاى سركوبگ تومور عمل كنند (Lin et al., 2010). يكى از عواملى كه مىتواند بر عملكرد miRNA تأثير بخذارد بلى مورفيسم تككنو كلئوتيدى (polymorphism, SNP single nucleotide) تحقيقات بسيارى براى فهم نقش تأثير آن بر بيان يا عملكرد آن (ازجمله تأثير آن بر استعداد ابتلا به سرطان و ديخر بيمارىها) انجام شده است. شناسايى SNP و تعيين همبستگى آنها با بيمارىهايى نظير سرطان مىتواند درك ليمك بهترى از ميزان خطر افراد در يك جمعيت رابه محققان بهدست

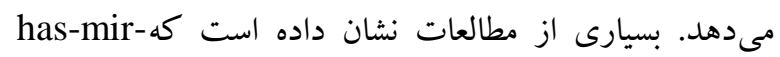
196a2 , rs11614913بهور درخور توجهى با استعداد ابتلا

به بيمارىهاى مختلف ازجمله سرطان ريه ( Tian et al., 2009)، سرطان سينه (Hu et al., 2009)، سرطان معده ،(Pi et al., 2010)، (Peng et al., 2010) سرطان كيسٔ صفرا (Srivastava et al., 2010)، سرطان يروستات (George et al., 2011)، و سرطان مرى Wang) et al., 2010) در جمعيت جِين انجام شده است، مشخص شد كه زنوتي؟ در مدل مغلوبيت (CC vs CT/TT) سبب كاهش خطر ابتلا به p=0.038, OR, 1.25; 95\% CI, 1.01 to ( ) سرطان مىشود

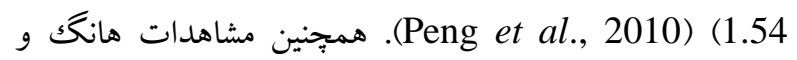

بررسى آمارى رگرسيون لجستيك درباره دادههاى تفكيك شده برحسب سن و جنس نشان داد كه مردان در مدل مغلوبيت كه در

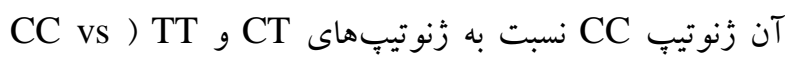
سنجيده مىشوند، داراى كاهش خطر ابتلا به سرطان (TT/CT (p=0. 01, OR, 0.42; 95\% CI, 0.22 to 0.81)

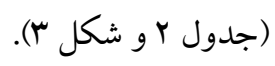

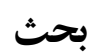

در سالهاى اخير، سرطان بهعنوان سومين عامل مرگكومير در ايران بساز بيمارىهاى قلبى و عروقى و تصادف شناخته شده

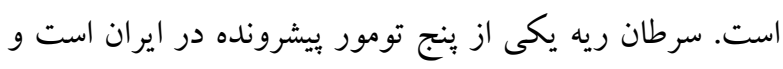

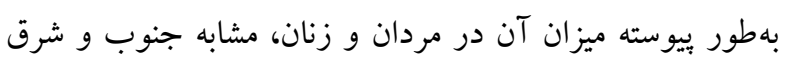
ارويا درحال افزايش است (Hosseini et al., 2014).

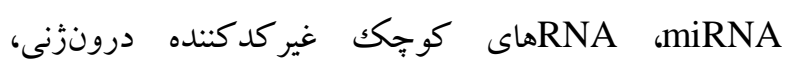
ريبونو كلئيك اسيد تككرشته (RNAs) هستند كه بيان زن را تنظيم مى كنند و در بسيارى از مسيرهاى مهم ازجمله مسيرهاى

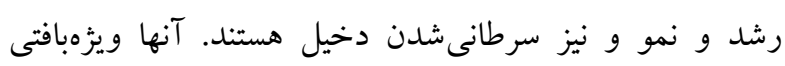
هستند و مشخص شده است كه بيان آنها (Tissue-specific) در سرطانها دجار بى نظمى مىشود (Lin et al., 2011). شواهد نشان مىدهد در سرطانهاى انسانى ازجمله سرطان سلولهاى غير كو جكك ريه، بيان برخى miRNA دجار تغيير مى شود و 
براى سرطان ريه در نظر گرفته شود (Hu et al., 2008)؛ البته در برخى جمعيتها جنين ارتباطى يافت نشده است. براى مثال

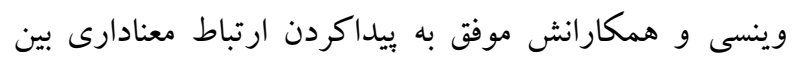

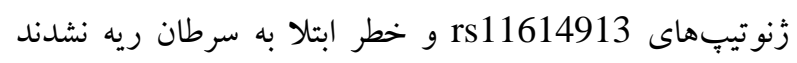
(Vinci et al., 2011) بيوماركر در ييش آگهى سرطان، SNP تحت مطالعه بايد

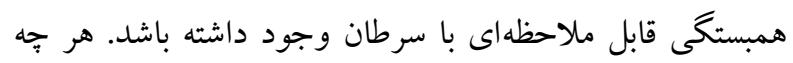

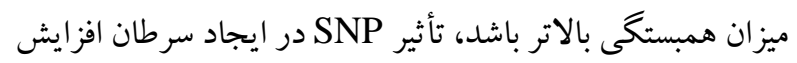

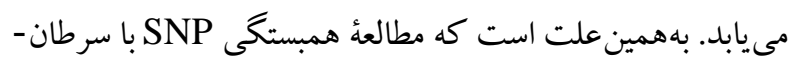
ها امروزه از اهميت زيادى برخوردار است. بهـ

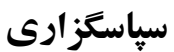

اين مطالعه با حمايت مركز تحقيقات سرطان دانشكاه علوم

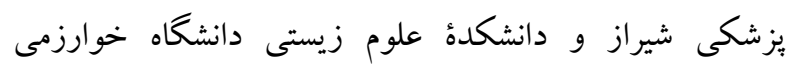

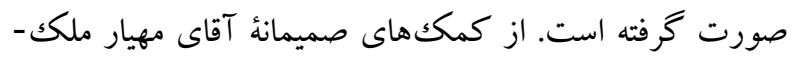
زاده از همكاران مركز تحقيقات سرطان شيراز در تأمين نمونه-

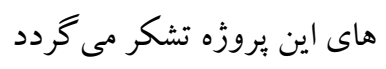

\section{References}

Ambros, V. 2003. MicroRNA pathways in flies and worms: growth, death, fat, stress, and timing. - Cell 113(2): 673-676.

Ambros, V. 2004. The functions of animal microRNAs. - Nature 16(431): 350-355.

Bartel, D.P. 2004. MicroRNAs: genomics, biogenesis, mechanism, and function. - Cell 116(2): 281-297.

Chen, C., Zhang, Y., Zhang, L., Weakley, S.M. and Yao, Q. 2011. MicroRNA-196: critical roles and clinical applications in development and cancer. - J. Cell. Mol. Med. 15(1): 14-23.

Christensen, B.C., Avissar-Whiting, M., Ouellet, L.G., Butler R.A., Nelson, H.H., McClean, M.D., Marsit, C.J. and Kelsey, K.T. 2010. Mature microRNA sequence polymorphism in MIR196A2 is associated with risk and prognosis of head and neck cancer. - Clin. Cancer Res. 16(14): 3713-3720.

Eslami Samarin, Z., Tahmaseb, M. and Ghaderi, A. 2015. Evaluation of single nucleotide polymorphism rs11614913 in mir196a2 with breast
همكارانش نشان داد كه زنوتيب CT/CC درمعرض خطر

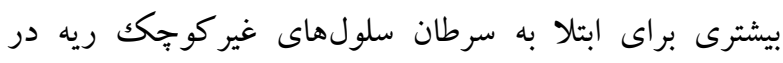

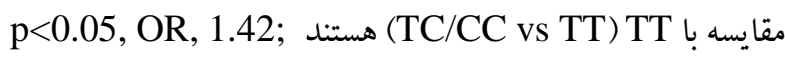
1.03 to 1.94(95\% CI,

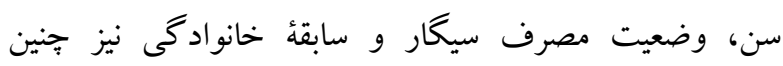

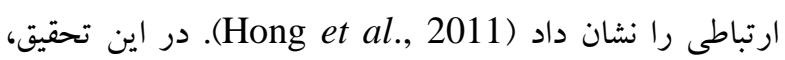

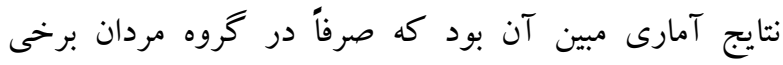

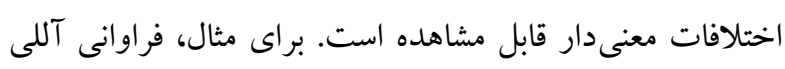

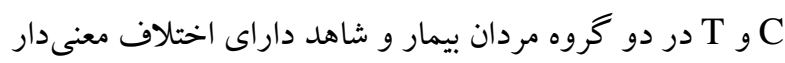

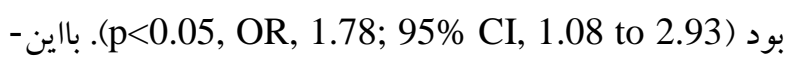
حال، SNP به دست آمده در برخى جوامع ارتباط معنىدارى با برخى سرطانها نشان نداده است ( Eslami Samarin et al.,

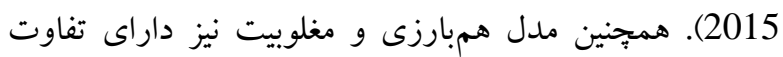

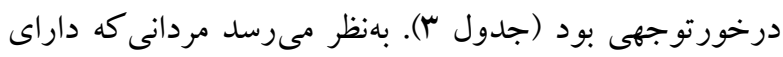

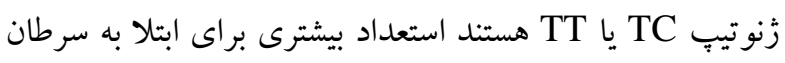

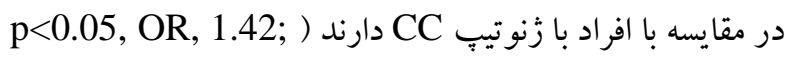
95\% CI, 1.03 to 1.94 هو و همكار انش بيشنهاد كردند كه

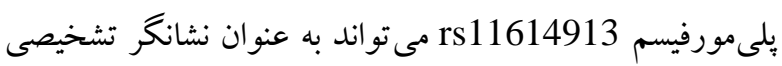

cancer susceptibility in Southern Iranian population. - Nova Biol. Rep. 2(3): 227-234.

Filipowicz, W., Bhattacharyya, S.N. and Sonenberg, N. 2008. Mechanisms of posttranscriptional regulation by microRNAs: are the answers in sight? - Nat. Rev. Genet. 9(2): 102-114.

George, G.P., Gangwar, R., Mandal, R.K., Sankhwar, S.N. and Mittal, R.D. 2011. Genetic variation in microRNA genes and prostate cancer risk in North Indian population. - Mol. Biol. Rep. 38: 1609-1615.

Hajmanoochehri, F., Mohammadi, N., Zohal, M.A, Sodagar, A. and Ebtehaj, M. 2014. Epidemiological and clinicopathological characteristics of lung cancer in a teaching hospital in Iran. - Asian. Pac. J. Cancer Prev. 15(6): 249524500 .

Hong, Y.S., Kang, H.J., Kwak, J.Y., Park, B.L., You, C.H., Kim, Y.M. and Kim, H. 2011. Association between microRNA196a2 rs11614913 genotypes and the risk of non-small cell lung cancer 
in Korean population. - J. Prev. Med. Public. Health 44(3): 125-130.

Hosseini, M., Naghan, P.A., Jafari, A.M., Yousefifard, M., Taslimi, S., Khodadad, K., Mohammadi, F., Sadr, M., Rezaei, M., Mortaz, E. and Masjedi, M.R. 2014. Nutrition and lung cancer: a case control study in Iran. - BMC. Cancer 14: 2-9.

Hu, Z., Chen, J., Tian, T., Zhou, X., Gu, H., Xu, L., Zeng, Y., Miao, R., Jin, G., Ma, H., Chen, Y. and Shen, H. 2008. Genetic variants of miRNA sequences and non-small cell lung cancer survival. J. Clin. Invest. 118(7): 2600-2608.

Hu, Z., Liang J., Wang, Z., Tian, T. and Zhou, X. 2009. Common genetic variants in pre-microRNAs were associated with increased risk of breast cancer in Chinese women. - Hum. Mut. 30: 79-84.

Lee, R.C., Feinbaum, R.L. and Ambros, V. 1993. The C. elegans heterochronic gene lin-4 encodes small RNAs with antisense complementarity to lin14. - Cell 75(5): 843-854.

Lin, P.Y. and Yang, P.C. Circulating miRNA signature for early diagnosis of lung cancer. EMBO. Mol. Med. 3(8): 436-437.

Lujambio, A. and Lowe, S.W. 2012. The microcosmos of cancer. - Nature 482:347-355.

Miller, S.A., Dykes, D.D. and Polesky, H.F. 1988. A simple salting out procedure for extracting DNA from human nucleated cells. - Nucleic Acid Res. 16(3): 1215-1216.

Min, K.T., Kim, J.W., Jeon, Y.J., Jang, M.J., Chong, S.Y., Oh, D. and Kim, N.K. 2012. Association of the miR-146aC>G, 149C>T, $196 \mathrm{a} 2 \mathrm{C}>\mathrm{T}$, and $499 \mathrm{~A}>\mathrm{G}$ polymorphisms with colorectal cancer in the Korean population. - Mol. Carcinog. 51: 65-73.

Mirtalebi, H., Heydari Nasrabadi, M. and Asadzadeh-Aghdaei, H. 2014. Association of miR196a2 (rs11614t913) polymorphism with colorectal cancer in Tehran population. - Med. Sci. J. Islamic Azad Uni. 23: 11-15.

Peng, S., Kuang, Z., Sheng, C., Zhang, Y. and Xu, H. 2010. Association of microRNA-196a-2 gene polymorphism with gastric cancer risk in a Chinese population. - Dig. Dis. Sci. 55: 2288-2293.

Lin, P.Y., Yu, S.L. and Yang, P.C. 2010. MicroRNA in lung cancer. - British J. Cancer 103: 1144-1148.

Qi, P., Dou, T.H., Geng, L., Zhou, F.G. and Gu, X. 2010. Association of a variant in MIR 196A2 with susceptibility to hepatocellular carcinoma in male Chinese patients with chronic hepatitis B virus infection. - Hum. Immunol. 71: 621-626.

Srivastava, K., Srivastava, A. and Mittal, B. 2010. Common genetic variants in premicroRNAs and risk of gallbladder cancer in North Indian population. J. Hum. Genet. 55: 495-499.

Tian, T., Shu, Y., Chen, J., Hu, Z. and Xu, L. 2009. A functional genetic variant in microRNA$196 \mathrm{a} 2$ is associated with increased susceptibility of lung cancer in Chinese. - Cancer Epidemiol. Biomarkers Prev. 18: 1183-1187.

Vinci, S., Gelmini, S., Pratesi, N., Conti, S., Malentacchi, F., Simi, L., Pazzagli, M., Orlando, C. 2011. Genetic variants in miR-146a, miR-149, miR-196a2, miR-499 and their influence on relative expression in lung cancers. - Clin. Chem. Lab. Med. 49(12): 2073-2080.

Wang, K., Guo, H., Hu, H., Xiong, G. and Guan, X. 2010. A functional variation in pre-microRNA$196 \mathrm{a}$ is associated with susceptibility of esophageal squamous cell carcinoma risk in Chinese Han. Biomarkers 15: 614-618.

Wood, S.L., Pernemalm, M., Crosbie, P.A. and Whetton, A.D. 2015. Molecular histology of lung cancer: from targets to treatments. - Cancer. Treat. Rev. 41(4): 361-75.

Pishva, P., Tahmaseb, M. and Ghaderi, A. 2016. Association between gene polymorphism rs11614913 in microRNA196a2, with Non-small cell lung cancer risk in the population of southern Iran. - Nova Biol. Rep. 3: 15-23.

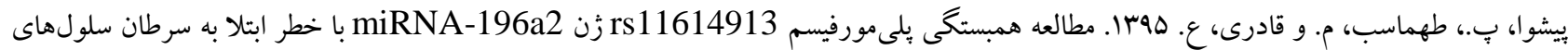

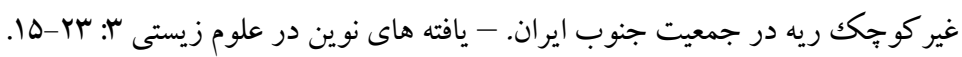

